\title{
A discussion of damage mitigation of natural disasters: How to increase citizens' preparedness
}

\author{
The 3rd Sustainability and Resilience Conference: Climate Change \\ 15 November 2021 \\ A1-4-1570760257 C2021 IEEE, SRC'21 \\ University of Bahrain
}

\author{
$1^{\text {st }}$ Hiroko Oe \\ The Faculty of Management \\ Bournemouth University \\ Bournemouth, UK \\ $\underline{\text { hoe@bournemouth.ac.uk }}$
}

\author{
$2^{\text {nd }}$ Yasuyuki Yamaoka \\ Department of Society and Industry \\ The Open University of Japan \\ Chiba, Japan \\ yamaoka-y@ouj.ac.jp
}

\begin{abstract}
It is widely recognised that community-wide support and learning is important to ensure that people are adequately prepared for natural disasters. To enhance preparedness of citizens, a critical theme is how to utilise the benefit of information Communication Technology (ICT) in the scheme of ICT-based learning programmes to raise citizens' perceptions of disaster risk and how to enable citizens to be ready for the future disasters. And in so doing, collaboration with the public sector, local disaster management NPOs and other stakeholders would be important topic. However, for such training programmes to be meaningful is important that they are based on citizens' sense of urgency about all aspects of disasters and a clear understanding by policy makers of what elements should be prioritised in the programme.

This study first recognises the existence of a gap between citizens' perceptions of the real and the virtual scape of natural disasters, and then, based on data from a survey of citizens' attitudes in X city in Japan, quantitatively captures the factors and elements of disasters that influence citizens' perceptions of city resilient, and suggests implications for policy makers and relevant stakeholders. The results will be presented to policy makers and stakeholders. This is expected to provide models and scales of analysis for ICT implementation in disaster prevention and mitigation, i.e. coping with natural disasters brought about by climate change.
\end{abstract}

Keywords - ICT implementations, natural disasters, preparedness, disaster mitigation, analytical model

\section{INTRODUCTION}

The various natural disasters brought about by climate change have become a problem all over the world, and coping with them has become a serious challenge [1]. This is also the case in Japan. For example, the number of special warnings for heavy rainfall in Japan has been increasing recently. These warnings are at the level of "please take action to save lives", and in recent years, 2019 has been the most frequent. In July
2021, a major landslide occurred in the Atami area of Shizuoka Prefecture, causing extensive damage. These landslides are typical of urban disasters, often derided as "man-made disasters caused by the concrete jungle", and are said to occur because asphalted roads and urban sewage systems are unable to absorb and treat unexpectedly high levels of rainfall, or because mountain villages have been reclaimed and converted into residential areas too quickly (Figure 1) [2].

It is widely acknowledged that community-wide support and learning are important for people to be adequately prepared for natural disasters. There is no doubt that the most effective way to enhance preparedness is through the collaborative development and implementation of programmes and continuous training by stakeholders such as the public sector and disaster prevention NPOs in the community. This is where ICT comes into its own, as preventive training schemes are conducted in a virtual environment to simulate a real disaster. However, in the face of the recent catastrophic natural disasters caused by unseasonable and extreme weather conditions, there is not yet a sufficient stockpile of systematic approaches that are easy to apply and implement. Hence, there is an urgent need to share practical guidance for relevant researchers and practitioners [3]. Certainly, there has been a lot of attention to the development of ICT-enabled programmes for preparedness, but this does not merely emphasise the need to have virtual training materials and platforms for training in disaster prevention and preparedness, but rather to prioritise any context or issue to help citizens Without knowing which contexts and issues should be prioritised for citizens' disaster preparedness training and awareness building, it is impossible to develop an adequate disaster management plan [4]. In other words, it is important to determine the content of the training programme after fully capturing the needs and demands of the citizens in the first instance. 


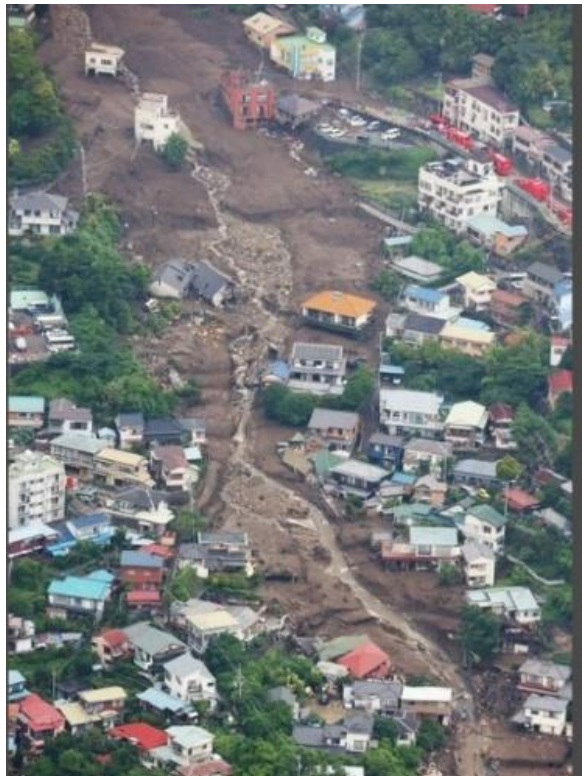

Figure 1 Atami disaster in July 2021 [2])

\section{ACADEMIC DISCUSSION}

\section{Climate change and contributions of ICT}

The International Telecommunication Union (ITU), the UN's specialized international agency for telecommunications, has set up study groups to address the issue of climate change using information and communication network infrastructures, and has held a series of discussions on ways to contribute to the solution. Typical examples include the following approaches:

- Using ICTs to combat climate change, the ITU [5] has developed international standards for energy-efficient solutions for telecommunications.

- Harmonisation of frequencies for disaster relief

- Increasing access to and connectivity of digital devices and raising awareness of climate change

The increasing human cost of climate change reminds us that mitigation and adaptation can only be successful if everyone is connected and has access to critical information and communications infrastructure [5]. The slogan there is \# Leave no one behind, and this spirit also corresponds to the SDGs.

In line with this policy, for example, in the UK, under the banner of sustainable and green ICT, a cross-departmental collaboration (Sustainable Technology Advice and Reporting - STAR) is a hub where a mixed team of government departments and organisations, academia, professional and technical bodies, and charities discuss measures to solve the problem.

Over the past decade of the Child's work in the UK, public interest in the relationship between environmental issues and ICT has been fluid. However, in recent years, ICTs and digital services have become "greener" through the adoption of new technologies and services that are smaller, lighter and more energy efficient, and as the ITU has declared, this characteristic of ICTs is one aspect of climate change that can contribute to global warming. As declared by the ITU, there is already a common understanding that this characteristic of ICT is one of the aspects that can contribute to the global warming problem.
The Fourth Industrial Revolution, known as the 4IR, has seen an increase in the functionality of ICT equipment, improved skills in the use and analysis of big data, as well as the latest ICT such as artificial intelligence (AI), blockchain and the Internet of Things (IOT). There is hope that the benefits of ICT will reduce the carbon emissions caused by the use of traditional equipment and reduce the global warming effect of this aspect. There is also the potential for a positive impact on global environmental protection through the reduction in energy use as machines and technology replace production processes that previously produced output through human labour. However, compared to the research and demonstration of the implementation-enhancing aspects of ICTs with such great potential, there is a significant policy challenge in increasing public preparedness to cope with the consequences of climate change and, increasingly, natural disasters that have happened or will probably happen again. The contribution of ICT to the challenge of disaster mitigation has not been well researched. This is the research gap that this study focuses on.

\section{Integration of real and virtual scapes in disasters}

Figure 2 shows the cognitive paradigm that should be recognized before the analysis of the research. 1.2 As mentioned in Section 1.2, in order for citizens to be able to act in a sufficiently protective manner when faced with a natural disaster, it is important to bridge the gap between real and virtual perceptions and to eliminate their fears and, conversely, their attitudes such as "this is a training exercise, there is no need to take it seriously". It is important to eliminate fears and attitudes such as "this is an exercise, we don't need to take it seriously". The framework (Figure 2) also suggests the importance of ensuring that the ICT-based virtual learning platform reflects citizens' awareness of disasters and covers priority topics.

In Japan, a country of natural disasters with frequent earthquakes and typhoons, there have been previous attempts to create prevention programmes to increase citizens' preparedness [7]. For example, when the Great Kanto Earthquake struck the Japanese capital, Tokyo, on 1 September 1923, it was just before noon and the kitchens of the predominantly wooden houses were on fire preparing for lunch, which is known to have caused extensive post-quake fire damage. Regular large-scale evacuation drills have been held to maintain and raise awareness of disaster prevention.

On the other hand, In fact, it is not easy to maintain the awareness of citizens to prepare for future disasters in disaster drills and disaster mitigation education [8]. In order to bridge this awareness gap, to increase citizens' preparedness for disasters that are not visible now but will probably come in the future, and to improve the efficiency of training, it is important to provide practical disaster training programmes by integrating visualised digital materials and virtual disaster experiences [9]. And, of course, in selecting the content and themes of the educational materials, it is necessary to clearly identify which disaster themes are in high demand by the public and which should be given priority.

\section{Integration of real and virtual scapes in disasters}

How, then, can social scientific perspectives, such as trust between citizens and government, and the ethical aspects of helping and assisting others in times of disaster, be considered 
in the ICT-based problem solving that is the subject of this study? This is the context in which interdisciplinary perspectives can be mobilised to examine disaster mitigation issues.

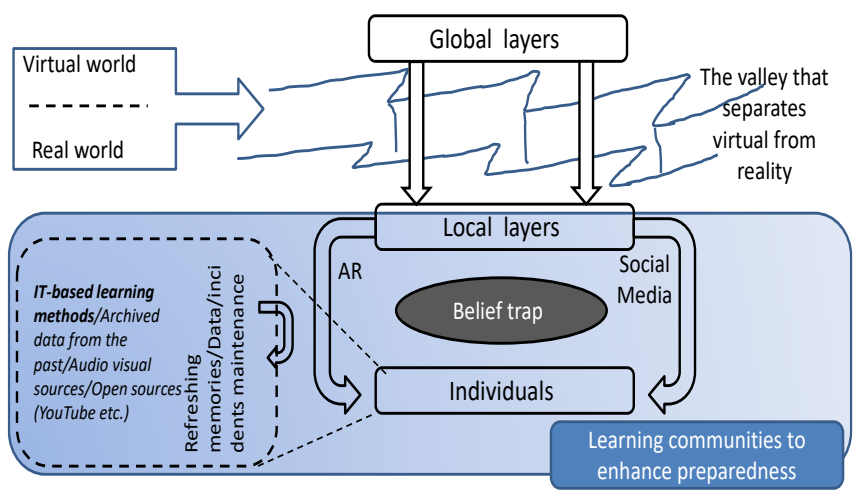

Figure 2. Virtual and real-word perception gap model (Adapted from [4] and [6])

Trust, for example, is a key issue in administrative guidelines and management in modern states, leading to a greater affinity between flexible and timely actions of government and political accountability [10]. The fact that trust in government, be it central or local government, or other public institutions or associations, leads to support for their interventions, which in turn leads to increased citizen commitment and engagement with government, has important implications for disaster mitigation planning. [11]; [12]; [13]. A number of studies have suggested that citizen trust should be one of the indicators to measure citizens' satisfaction with government [10]; [14]. As Julian and Ross [15] state, the creation of a "safe" infrastructure for disaster prevention and mitigation is one of the most important policies to protect citizens' lives and property in a country that is vulnerable to a wide variety of natural disasters brought about by climate change. In other words, increasing citizens' satisfaction with disaster prevention and mitigation policies and fostering their trust in public interventions can be expected to increase their commitment to the Action Programme for Disaster Reduction, the subject of this study, and their awareness of disaster prevention and mitigation [4].

\section{ANALYSIS, DISCUSSION, AND PROPOSITION OF CONCEPUTUAL MODEL}

\section{Perceptions of citizens for mitigation policies}

We selected 12 questions related to city resilience (using a Likert 5-point response system) from the Citizen Attitudes Survey administered to citizens of X City, and applied factor analysis to this data set to generate three latent factors. Four observed variables were classified for each of the three factors, and the values of Cronbach's alpha of the three generated factors were greater than 0.6 , which is the minimum requirement for validating the reliability of the factors. Therefore, the attained three factors can be judged to explain the data set and are three indicators that constitute the citizens' security and trust in the municipal administration (Table 1).
Table 1 Three factors that constitute the evaluation of the city's resilience

\begin{tabular}{|c|c|c|c|c|}
\hline & \multicolumn{3}{|c|}{ Components } & \multirow[b]{2}{*}{ Alpha } \\
\hline & 1 & 2 & 3 & \\
\hline NPO activities support vulnerable citizens & 0.763 & 0.040 & 0.233 & \multirow{4}{*}{0.844} \\
\hline Adivce centre and training & 0.736 & 0.136 & 0.185 & \\
\hline $\begin{array}{l}\text { Lifelong learning support and sustainable } \\
\text { education for communities }\end{array}$ & 0.734 & 0.052 & 0.197 & \\
\hline Community activities support & 0.721 & 0.077 & 0.263 & \\
\hline Flood damage prevention & 0.165 & 0.691 & $0.050^{\top}$ & \multirow{4}{*}{0.731} \\
\hline Disaster prevention reinforcement & 0.186 & 0.686 & 0.107 & \\
\hline Fire Department & 0.253 & 0.595 & 0.162 & \\
\hline Anti-Crime, Street Safety & 0.112 & 0.588 & 0.292 & \\
\hline Environmental preservation & 0.265 & 0.225 & 0.666 & \multirow{4}{*}{0.721} \\
\hline Cityscapes and safe urban environments & 0.132 & 0.098 & 0.649 & \\
\hline $\begin{array}{l}\text { Ensuring mobility and maintenance of the } \\
\text { transport network, including strong guardrails } \\
\text { and footbridges }\end{array}$ & 0.264 & 0.222 & 0.626 & \\
\hline City road maintenace & 0.192 & 0.248 & 0.608 & \\
\hline
\end{tabular}

a. Rotation converged in 6 iterations.

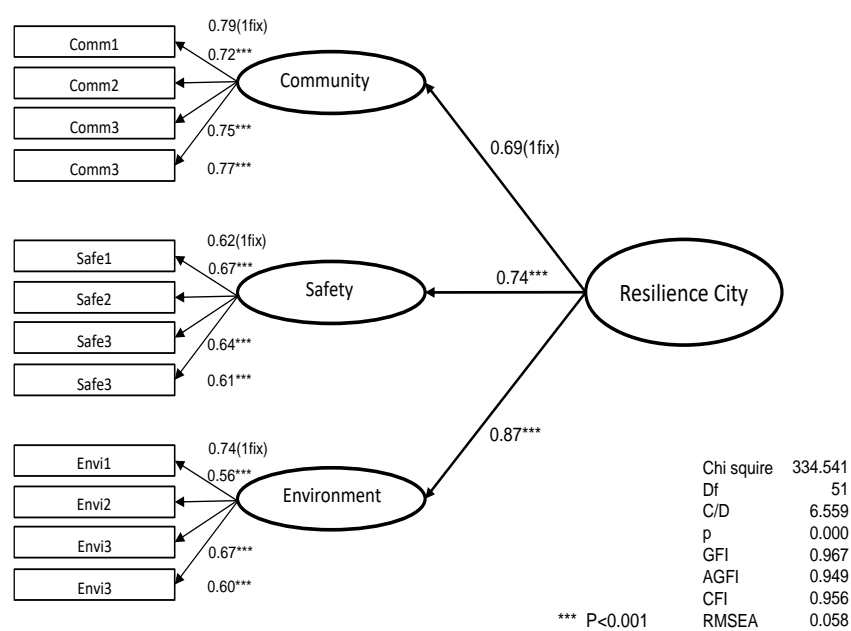

Figure 3 SEM Research Model for Resilience city (Second Order Factor Analysis Model)

The three factors obtained and a total of 12 observed variables were fed into Structured Equation Modelling (SEM) to study the path taken by citizens to assess the city's resilience. For the analysis, SPSS ver26 and AMOS ver26 were used; the results of the SEM are shown in Figure 3.

As shown in Table 2, each of the three factors effectively shapes citizens' assessment of their city's resilience. Of the three factors-community, safety, and environment-the one that contributes the most to resilience awareness is comprehensive environmental development, followed by safety assurance, such as current disaster prevention and flood control.

Based on some more detailed investigation into the dataset with two different citizens' groups, there has been found a significant difference between the ratings of citizens who have experienced flooding and those who have not aware of virtual disaster prevention and mitigation during training prior to a disaster, as shown in Figure 2. 
Table 2 Path coefficients and the model fitness

\begin{tabular}{|c|c|c|c|}
\hline To & From & $\begin{array}{c}\text { Path } \\
\text { coefficient }\end{array}$ & $\mathrm{p}$ \\
\hline Community & $<--\quad$ Resilience City & 0.691 & 1fix \\
\hline Safety & $<--$ Resilience City & 0.741 & $* * *$ \\
\hline Environment & $<--\quad$ Resilience City & 0.869 & $* * *$ \\
\hline Comml & $<---$ Community & 0.791 & 1fix \\
\hline Comm2 & $<---$ Community & 0.717 & $* * *$ \\
\hline Comm3 & $<---$ Community & 0.766 & $* * *$ \\
\hline Comm4 & $<---$ Community & 0.747 & $* * *$ \\
\hline Safe1 & $<--\quad$ Safety & 0.620 & 1fix \\
\hline Safe2 & $<---\quad$ Safety & 0.671 & $* * *$ \\
\hline Safe3 & $<--\quad$ Safety & 0.643 & $* * *$ \\
\hline Safe4 & $<--\quad$ Safety & 0.606 & $* * *$ \\
\hline Envil & $<--$ Environment & 0.737 & 1fix \\
\hline Envi2 & <--- Environment & 0.560 & $* * *$ \\
\hline Envi3 & <-- Environment & 0.671 & $* * *$ \\
\hline Envi4 & <--- Environment & 0.599 & $* * *$ \\
\hline \multicolumn{2}{|l|}{ Chi squire (C) } & 334.541 & \\
\hline \multicolumn{2}{|c|}{ Degree of freedom (D) } & 51.000 & \\
\hline \multicolumn{2}{|l|}{$\mathrm{C} / \mathrm{D}$} & 6.559 & \\
\hline \multicolumn{2}{|l|}{ Provability (P) } & 0.000 & \\
\hline \multicolumn{2}{|c|}{ Goodness of fit index (GFI) } & 0.967 & \\
\hline \multicolumn{2}{|c|}{ Adjusted goodness of fit index (AGFI) } & 0.949 & \\
\hline \multicolumn{2}{|c|}{ Comparative fit index (CFI) } & 0.956 & \\
\hline \multicolumn{2}{|c|}{ Root mean square error of approximation (RMSEA) } & 0.058 & \\
\hline
\end{tabular}

Note 1: 1fix means coefficient value was fixed as 1

Note 2 : *** means $\mathrm{p}<0.001$

We focuses on the differences in the evaluation of "Flood damage prevention" between citizens who have experienced flooding and those who have not. it is found that There is an obvious difference in the behaviour of the two groups of citizens, those who have experienced the previous flood or not. This means that citizens who have experienced floods are more aware of the importance of disaster prevention and mitigation measures, whereas those who have not experienced floods are less aware of the urgency and importance of such measures. This suggests how important it is for both citizens and the municipal government to be prepared, along with public sector policy interventions, to increase perceptions of the criticality of reduction of potential risk in advance, for example through disaster evacuation drills, before the actual disaster strikes.

\section{ICT implementations: How to embed preparedness in citizens' mind-set}

Risk management against natural disasters is important in a twofold sense, one is the efforts to reduce the disaster itself, and the other is the improvement of citizens' prepardness through the implementation of ICT for disaster reduction, as was the main focus of this study. This second issue can be expected to create a platform to ensure safety and security for citizens by redesigning communities as "learning organizations" as discussed in the previous section. Community-based lifelong education programmes to help citizens prepare for natural disasters can benefit from the tools of virtual learning, and this is already being done by many local authorities in Japan, a disaster-prone country. However, a practical and effective model for bridging the psychological gap and instilling the lessons that will lead to the real behavioural changes needed in a real disaster is still being designed. The use of e-learning to support citizen learning and improve preparedness is a fundamental approach, but the sectors most affected by disasters are the vulnerable, and any citizen can be vulnerable.

As Oe \& Kawakami [4] argue, in the case of natural disasters, for instance, the 3.11 Great East Japan Earthquake in Japan also highlighted the problem of information gaps faced by socially vulnerable groups such as disabled people or isolated elderly citizens. In the event of a real disaster, policymakers and researchers need to be prepared to implement ICTs to provide accurate evacuation information, food security and other important information to the informationally vulnerable, and to design effective learning processes to be effective in the event of a real disaster. It is necessary to design the system so that it can be effective, and to evaluate it and improve the system tirelessly. From the perspective of learning styles and methods, Oe [17] proposes a training and learning schemes using the etude method based on the case-lead approach, where immersive and other techniques enabled by advanced ICT would be the technology to be applied [18]. However, despite its great potential and possibilities, the concept of immersion in the design of disaster prevention and learning modules has not yet been fully explored, and it would be useful to take measures to increase the immersion of virtual learning-based learning experiences in the future [19].

A concept covering the stakeholder networks and key actors that support "learning organisations" that should be designed from the perspective of risk management against natural disasters is shown in Figure 4.

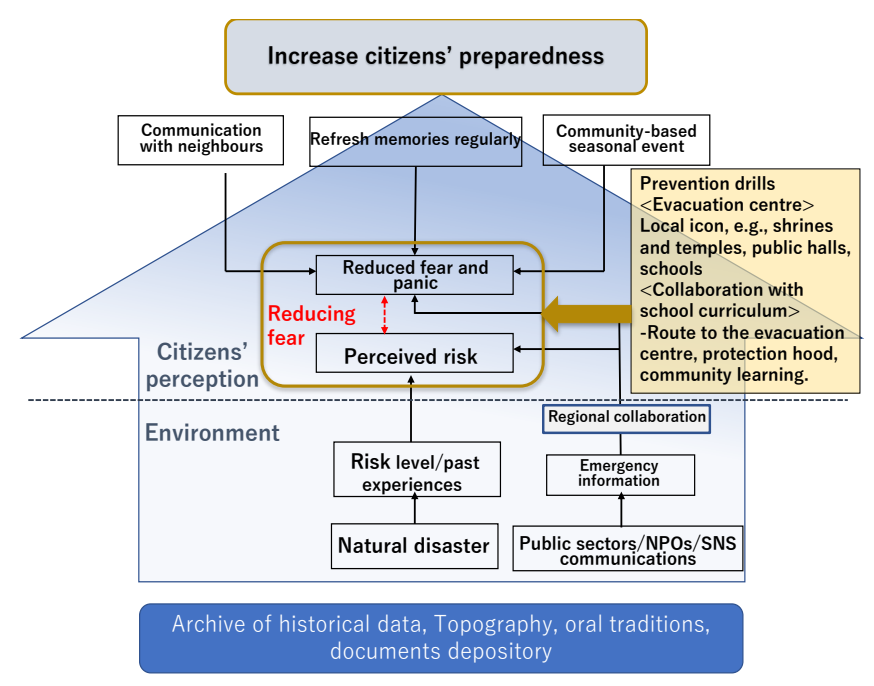

Figure 4 Conceptual framework for mitigation programme

It awaits the development of a collaborative social system where communities learn from and support each other as part of a lifelong learning process that covers a different range of subjects than those taught in schools. It is important to involve a diverse range of citizens, including those most vulnerable to the effects of disasters, and to identify which elements of the disaster prevention and mitigation framework are most urgent and which should be prioritised by these "service recipients".

As indicated in Section III, it is necessary for the effectiveness of such a study programme to include items that citizens, as the "recipients of services", perceive as priorities to be addressed in the first place. It is also necessary to announce clearly that the government is willing to listen to citizens' voices and to consider policy frameworks that 
support citizens' safe and secure lives, which will stimulate citizens' willingness and commitment to participate in learning programmes.

\section{CONCLUSION}

This study examines how ICT can contribute to the policy issue of disaster prevention and mitigation through improving citizens' prepardness to natural disasters by proposing and discussing a conceptual model of a disaster prevention and mitigation programme (Figure 4). Disaster prevention drills are a core action in citizens' disaster preparedness, and although training programmes for disaster prevention have traditionally been implemented at the municipal level in disaster-prone countries such as Japan, a systematic approach has never been realized. This has meant that relevant researchers and policymakers have not been able to share solid guidance and courses of action, nor has there been an agreed framework for validation to review, implement and evaluate policies [20]. The findings of this study can be expected to serve not only as an important guidepost for stakeholders considering policies in the field of disaster prevention and mitigation through ICT implementation, but also as an engager to invite citizens in community-based activities, including disaster management activities.

For the future research plan, it is important to verify the usefulness of the proposed action plan, which contains important elements. The results of the implementation of the disaster management schemes proposed here should be examined to closely unravel the ways in which ICT can contribute to disaster management and the spread of awareness among people, as well as protect the safety of citizens.

\section{REFERENCES}

[1] ITU The International Federation of Red Cross and Red Crescent, Disaster preparedness, 2021. https://media.ifrc.org/ifrc/what-wedo/disaster-and-crisis-management/disaster-preparedness/ (accessed 30 August 2021)

[2] Yahoo Japan. Atami landslide draws attention to 27 'high-risk built-up areas' hidden in Tokyo and Osaka, 2021 https://news.yahoo.co.jp/articles/711137495b46249ce802ed0cdfa90a 821a4a3aff (accessed 30 August 2021)

[3] Hangartner, R. B., Totura, C. M. W., Labouliere, C. D., Gryglewicz, K., \& Karver, M. S. Benchmarking the "Question, Persuade, Refer" program against evaluations of established suicide prevention gatekeeper trainings. Suicide and Life - Threatening Behavior, 2019. vol. 4 no 2, pp. 353-370.

[4] Oe, H., \& Kawakami, S. A disaster prevention programme using virtual schemes: Recommendation of tradition populaire integrated with tendenko as an approach to immersive training. International Journal of Disaster Risk Reduction, 2021. 102135

[5] ITU Environment and climate Change, 2021. https://www.itu.int/en/action/environment-and-climatechange/Pages/default.aspx (accessed 31 August 2021)

[6] Mitsuhara, H. The present and future of ICT-based disaster education system, Journal of Japanese Society for Information and Systems in Education, 2018. vol. 35 no. 2, pp. 66-80.

[7] Yanagawa, Y., Takeuchi, I., Jitsuiki, K., Yoshizawa, T., Ishikawa, K., Omori, K. \& Osaka, H. Disaster Imagination Game at Izunokuni City for preparedness for a huge Nankai Trough earthquake, Scholars Journal of Applied Medical Sciences, 2016. vol. 4 no. 6D, pp. 21292132 .

[8] Guo, Y., \& Li, Y. Getting ready for mega disasters: the role of past experience in changing disaster consciousness. Disaster Prevention and Management, 2016. vol. 25 no. 4, pp. 492-505.
[9] Palen, L., \& Liu, S. B. Citizen communications in crisis: anticipating a future of ICT-supported public participation. In Proceedings of the SIGCHI conference on Human factors in computing systems, 2007. pp. 727-736.

[10] Cooper, C. A., Knotts, H. G. and Brennan, K. M. The Importance of Trust in Government for Public Administration: The Case of Zoning, 2008. pp. 459

[11] Garcia, G. A. and Gaytan, E. A. Trust in Spanish governments: Antecedents and consequences. Economic Analysis and Policy, 2013. vol. 43 no. 2 , pp. 177.

[12] Myung, J. Citizen Participation, Trust, and Literacy on Government Legitimacy: The Case of Environmental Governance. Journal of Social Change, 2013. vol. 5 no. 1, pp. 11-25.

[13] Smith, J. W., Leahy, J. E., Anderson, D. H. and Davenport, M. A. Community/agency trust and public involvement in resource planning. Society \& Natural Resources, 2013. vol. 26 no. 4, 452-471.

[14] Morgeson, F. V. Expectations, Disconfirmation, and Citizen Satisfaction with the US Federal Government: Testing and Expanding the Model. Journal of Public Administration Research \& Theory, 2013. vol. 23 no. 2 , pp. 289-305.

[15] Julian, D. A., and Ross, M.. Strengthening Infrastructure and Implementing Functions to Support Collaborative Community Problem Solving. Journal of Planning Literature, 2013. vol. 28 no.2, pp. 124-134.

[16] Herian, M. N. and Tomkins, A. J. Citizen Satisfaction Survey Data: A Mode Comparison of the Derived Importance-Performance Approach. American Review of Public Administration, 2012. vol. 42 no. 1, pp. 66-86.

[17] Oe, H. A study on the learning process of sustainable community design: from the process of etude based on the case method approach, Departmental Bulletin Paper, Yokohama National University, 2011a. vol. 32 no. 1 , pp. $99-112$.

[18] Lovreglio, R., and Kinateder, M. Augmented reality for pedestrian evacuation research: promises and limitations. Safety science, 2020. vol. 128, 104750., in press.

[19] Solinska-Nowak, A., Magnuszewski, P., Curl, M., French, A., Keating, A., Mochizuki, J., Liu, W., Mechlera, R., Kulakowskab, M., and Jarzabek, L. An overview of serious games for disaster risk management-Prospects and limitations for informing actions to arrest increasing risk. International journal of disaster risk reduction, 2018. vol. 31, pp. 1013-1029.

[20] Oe, H. A study of risk communication and interactive understanding, Departmental Bulletin paper, 2011b. vol. 32 no. 3/4, pp. 37-53. 